\title{
CUFF PRESSURES IN INTENSIVE CARE UNITS; HOW CORRECT ARE WE?
}

\author{
Vishak Surendra1, Ajith Nilakantan²
}

${ }_{1}^{1}$ Assistant Professor, Department of ENT, Father Muller Medical College, Mangalore, Karnataka. 2HOD, Department of ENT, Armed Forces Medical College, Pune.

\section{ABSTRACT}

\section{BACKGROUND}

In patients on ventilator support in intensive care units, inflation of the cuff of the endotracheal tube/tracheostomy tube within the correct range of pressure is of critical importance. Overinflation also has to be avoided as it may lead to complications like tracheooesophageal fistula, innominate artery fistula and laryngeal stenosis. Underinflation increases the chances of aspiration and pneumonia. The acceptable range of cuff pressure is taken as $20-30 \mathrm{~cm} \mathrm{H}_{2} \mathrm{O}$.

Aims and Objectives - This clinical study aims to determine the adequacy of cuff pressure inflation in the intensive care unit of a tertiary care hospital, when done by residents and paramedical personnel, and infer whether routine use of cuff pressure monitor needs to be practised.

The specific objectives are-

1. To determine whether there is any difference in the adequacy of cuff pressure inflation, when performed by residents and by paramedical personnel.

2. To determine whether there is a requirement for either residents or paramedical personnel to use cuff pressure monitor in order to achieve correct cuff pressure.

\section{MATERIALS AND METHODS}

A blinded observational study was carried out in the intensive care unit of a tertiary care hospital on patients on ventilatory support through either a tracheostomy tube or an endotracheal tube by objective measurement of the cuff pressure with a cuff pressure monitor. 120 such measurements were taken, 60 on cuffs inflated by residents and 60 on cuffs inflated by paramedical personnel, who used the commonly practised palpation method. Taking the correct range of cuff pressure to be $20-30 \mathrm{~cm} \mathrm{H}_{2} \mathrm{O}$, the correctness of the pressure achieved by residents and paramedical personnel was determined.

\section{RESULTS}

1. Out of the 120 readings by both residents and paramedical personnel, $26(21.66 \%)$ were $<20 \mathrm{~cm}$ of $\mathrm{H}_{2} \mathrm{O}, 60(50 \%)$ were $20-30$ $\mathrm{cm}$ of $\mathrm{H}_{2} \mathrm{O}$ and $34(28.33 \%)$ were $>30 \mathrm{~cm}$ of $\mathrm{H}_{2} \mathrm{O}$.

2. Out of the 60 readings of residents, 10 were $<20 \mathrm{~cm}$ of $\mathrm{H}_{2} \mathrm{O}, 42$ were in the correct range of pressure i.e. between 20 and $30 \mathrm{~cm}$ of $\mathrm{H}_{2} \mathrm{O}$ and 08 readings were $>30 \mathrm{~cm}$ of $\mathrm{H}_{2} \mathrm{O}$.

3. Out of the 60 readings by paramedical personnel, 16 were $<20 \mathrm{~cm}$ of $\mathrm{H}_{2} \mathrm{O}, 18$ were in the correct range of pressure i.e. between 20 and $30 \mathrm{~cm}$ of $\mathrm{H}_{2} \mathrm{O}$ and 26 readings were $>30 \mathrm{~cm}$ of $\mathrm{H}_{2} \mathrm{O}$.

4. $70 \%$ of readings of residents were in the correct range of pressure i.e. between 20 and $30 \mathrm{~cm}$ of $\mathrm{H}_{2} \mathrm{O}$ whereas only $30 \%$ of readings of paramedical personnel were in the correct range of pressure.

\section{CONCLUSION}

After the analysis of the results, it is clear that only $50 \%$ of the measured cuff pressures are in correct range. Residents were more accurate in attaining correct cuff pressures than paramedical staff. Cuff pressure monitor should be routinely used for cuff pressure inflation and to check the adequacy of inflation in intubated/tracheostomised patients. There is a need to impart the importance of using cuff pressure monitor in routine practice.

\section{KEYWORDS}

Cuff Pressure, ICU.

HOW TO CITE THIS ARTICLE: Surendra V, Nilakantan A. Cuff pressures in intensive care units; how correct are we?. J. Evolution Med. Dent. Sci. 2016;5(96):7056-7059, DOI: 10. 14260/jemds/2016/1596

Financial or Other, Competing Interest: None.

Submission 26-10-2016, Peer Review 19-11-2016,

Acceptance 25-11-2016, Published 01-12-2016.

Corresponding Author:

Dr. Vishak Surendra,

Department of ENT,

Father Muller Medical College,

Mangalore.

E-mail: vishoo1980@gmail.com

DOI: $10.14260 /$ jemds/2016/1596

(c) (i) $\odot$

\section{BACKGROUND}

Intensive care unit is an integral part of modern day medicine. In patients in the ICU, two methods of securing airway are by endotracheal tubes and tracheostomy tubes which are cuffed. In patients on ventilator support in intensive care units, inflation of the cuff of the endotracheal tube/tracheostomy tube within the correct range of pressure is of critical importance. A critical function of the endotracheal tube cuff is to seal the airway, thus preventing aspiration of pharyngeal contents into the trachea and to ensure that there are no leaks past the cuff during positive pressure ventilation. 
Pressure should be enough to achieve airway seal so that aspiration and gas leaks are prevented. The acceptable range of cuff pressure is taken as $20-30 \mathrm{~cm} \mathrm{H}_{2} \mathrm{O} .(1,2)$

Complications have been associated with insufficient cuff inflation. Consequences of microaspiration of oropharyngeal secretions include nosocomial pulmonary infections.(3) Overinflation also has to be avoided as it may lead to complications like tracheo-oesophageal fistula, innominate artery fistula and laryngeal stenosis. Conventional highvolume; low-pressure cuffs may not prevent micro-aspiration even at cuff pressures up to $60 \mathrm{~cm} \mathrm{H}_{2} \mathrm{O}$, although some studies suggest that only $25 \mathrm{~cm} \mathrm{H} \mathrm{H}_{2} \mathrm{O}$ is sufficient. In contrast, newer ultra-thin cuff membranes made from polyurethane effectively prevent liquid flow around cuffs inflated only to $15 \mathrm{~cm} \mathrm{H}_{2} \mathrm{O}$.(4) In the absence of clear guidelines, many clinicians consider 20 $\mathrm{cm} \mathrm{H}_{2} \mathrm{O}$ a reasonable lower limit for cuff pressure in adults.

Most doctors/paramedical personnel rely on palpation of the external balloon to determine adequacy of cuff inflation. However, an objective method of measuring the cuff pressure with a small aneroid manometer is available.(5) There is limited data comparing the correctness of cuff pressure when done by palpation method as opposed to using an aneroid manometer.

This study aims to determine the adequacy of cuff pressure inflation, when done by residents and paramedical personnel by palpation method and to infer whether routine use of cuff pressure monitor needs to be practised.

\section{Aims and Objectives}

This clinical study aims to determine the adequacy of cuff pressure inflation in the intensive care unit of a tertiary care hospital, when done by residents and paramedical personnel, and infer whether routine use of cuff pressure monitor needs to be practised.

\section{The Specific Objectives are}

1. To determine whether there is any difference in the adequacy of cuff pressure inflation, when performed by residents and by paramedical personnel.

2. To determine whether there is a requirement for either residents or paramedical personnel to use cuff pressure monitor in order to achieve correct cuff pressure.

\section{MATERIALS AND METHODS}

College Ethical Committee approval was taken. The study was performed on patients on ventilatory support through either a tracheostomy tube or an endotracheal tube, in the intensive care unit of a tertiary care hospital. A blinded observational study was carried out comparing cuff pressures by digital palpation with objective measurement of the cuff pressure with TRACOE cpm handheld aneroid manometer. The observer was blinded as to whether the cuff was inflated by residents or paramedical personnel.

120 such measurements were taken, 60 on cuffs inflated by residents and 60 on cuffs inflated by paramedical personnel, who used the commonly practised palpation method. The sizes of the endotracheal tubes were size 7 and 7.5 in females and 8 and 8.5 in males. Taking the correct range of cuff pressure to be $20-30 \mathrm{~cm} \mathrm{H}_{2} \mathrm{O}$, the correctness of the pressure achieved by residents and paramedical personnel was determined. A comparison of the correctness of readings between residents and paramedical personnel was done.

Based on the accuracy achieved by inflation by palpatory method, the requirement for either residents or paramedical personnel to use cuff pressure monitor in order to achieve correct cuff pressure was determined. The results were analysed statistically using SPSS software 16.0.

\section{RESULTS}

The study was performed on patients on ventilatory support through either a tracheostomy tube or an endotracheal tube, in the intensive care unit of a tertiary care hospital. A blinded observational study was carried out by objective measurement of the cuff pressure in these cases with a cuff pressure monitor. 120 measurements were taken, 60 on cuffs inflated by residents and 60 on cuffs inflated by paramedical personnel, who used the commonly practised palpation method. There were 15 cases with tracheostomy tubes and 45 cases with endotracheal tubes. Readings were taken from each case twice, once after inflation by a resident and once after inflation by paramedical personnel. The cases included 11 females and 49 males.

Overall distribution of Cuff pressures in 120 readings by both residents and the paramedical personnel showed that cuff pressures in $21.66 \%(\mathrm{n}=26)$ were $<20 \mathrm{~cm} \mathrm{H} \mathrm{H}_{2} \mathrm{O}, 50 \%$ ( $n=60)$ were $20-30 \mathrm{~cm} \mathrm{H}_{2} \mathrm{O}$ and $28.33 \%(\mathrm{n}=34)$ were $>30 \mathrm{~cm}$ $\mathrm{H}_{2} \mathrm{O}$ [Diagram 1].

Out of the 60 readings of residents, $10(16.66 \%)$ were $<20$ $\mathrm{cm}$ of $\mathrm{H}_{2} \mathrm{O}, 42(70 \%)$ were in the correct range of pressure i.e. between $20-30 \mathrm{~cm}$ of $\mathrm{H}_{2} \mathrm{O}$ and 08 (13.33\%) readings were $>30$ $\mathrm{cm}$ of $\mathrm{H}_{2} \mathrm{O}$. Out of the 60 readings by paramedics, 16 (26.66\%) were $<20 \mathrm{~cm}$ of $\mathrm{H}_{2} \mathrm{O}, 18(30 \%)$ were in the correct range of pressure i.e. between 20 and $30 \mathrm{~cm}$ of $\mathrm{H}_{2} \mathrm{O}$ and 26 (43.33\%) readings were $>30 \mathrm{~cm}$ of $\mathrm{H}_{2} \mathrm{O}$ [Table 1].

The data was analysed statistically using SPSS 16.0. The differences in the cuff pressure inflation between the two subsets were found to be statistically significant $(P<0.05)$.

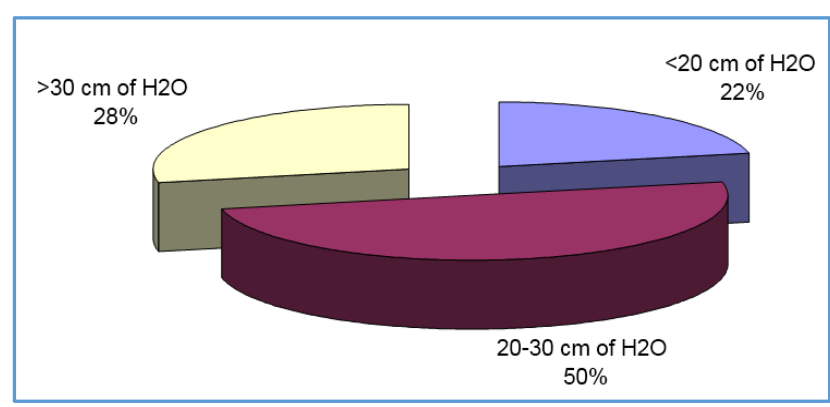

Diagram 1. Overall Distribution of Cuff Pressure Readings by Palpatory Method

\begin{tabular}{|c|c|c|c|c|}
\hline & $\begin{array}{c}<\mathbf{2 0} \mathbf{~ c m} \\
\text { of } \mathbf{H}_{\mathbf{2}} \mathbf{0}\end{array}$ & $\begin{array}{c}\mathbf{2 0 - 3 0} \mathbf{~ c m} \\
\mathbf{o f} \mathbf{H}_{\mathbf{2}} \mathbf{O}\end{array}$ & $\begin{array}{c}>\mathbf{3 0} \mathbf{~ c m} \\
\mathbf{o f ~} \mathbf{H}_{\mathbf{2}} \mathbf{0}\end{array}$ & $\mathbf{n}$ \\
\hline Residents & $\begin{array}{c}10 \\
(16.66 \%)\end{array}$ & $\begin{array}{c}42 \\
(70 \%)\end{array}$ & $\begin{array}{c}08 \\
(13.33 \%)\end{array}$ & $\begin{array}{c}\mathrm{n} \\
=60\end{array}$ \\
\hline $\begin{array}{c}\text { Paramedical } \\
\text { personnel }\end{array}$ & $\begin{array}{c}16 \\
(26.66 \%)\end{array}$ & $\begin{array}{c}18 \\
(30 \%)\end{array}$ & $\begin{array}{c}26 \\
(43.33 \%)\end{array}$ & $\begin{array}{c}\mathrm{n} \\
=60\end{array}$ \\
\hline
\end{tabular}

Table 1. Frequency Distribution of Cuff Pressure Readings among Residents and Paramedical Personnel

\section{DISCUSSION}

In patients on ventilator support in intensive care units, inflation of the cuff of the endotracheal tube/tracheostomy tube within the correct range of pressure is of critical importance. The acceptable range of cuff pressure is taken as $20-30 \mathrm{~cm} \mathrm{H}_{2} \mathrm{O} .(6,7,8,9,10)$ 
Overinflation has to be avoided as it may lead to complications like tracheo-oesophageal fistula, innominate artery fistula and laryngeal stenosis. Underinflation increases the chances of aspiration and pneumonia.(11)

Previous studies suggest that the cuff pressure is not accurately measured by palpation method. Papiya Sengupta et al(12) observed that measured cuff pressure exceeded $40 \mathrm{~cm}$ $\mathrm{H}_{2} \mathrm{O}$ in $27 \%$ of patients, $30 \mathrm{~cm} \mathrm{H}_{2} \mathrm{O}$ in $50 \%$ of patients and were less than $20 \mathrm{~cm} \mathrm{H}_{2} \mathrm{O}$ in $23 \%$ of patients. Cuff pressures were thus less likely to be within the recommended range (20-30 $\mathrm{cm} \mathrm{H}_{2} \mathrm{O}$ ) than outside the range. Braz et al(13) observed cuff pressure exceeding $40 \mathrm{~cm} \mathrm{H}_{2} \mathrm{O}$ in $91 \%$ of PACU patients after anaesthesia with nitrous oxide, $55 \%$ of ICU patients, and $45 \%$ of PACU patients after anaesthesia without nitrous oxide. In an experimental study, Fernandez et al(14) observed that when the cuff was inflated randomly to 10,20 , or $30 \mathrm{~cm} \mathrm{H}_{2} \mathrm{O}$, participating physicians and ICU nurses were able to identify the group in $69 \%$ of the high-pressure cases, $58 \%$ of the normal pressure cases, and $73 \%$ of the low pressure cases. Cuff overinflation rates have been found to be 55 to $62 \%$.(15)

In our study, we found that out of the 120 readings by both residents and paramedical personnel, $26(21.66 \%)$ were $<20$ $\mathrm{cm}$ of $\mathrm{H}_{2} \mathrm{O}, 60$ (50\%) were $20-30 \mathrm{~cm}$ of $\mathrm{H}_{2} \mathrm{O}$ and 34 (28.33\%) were $>30 \mathrm{~cm}$ of $\mathrm{H}_{2} \mathrm{O}$. This result has been found comparable to the previous studies even though high pressure cases are lesser.

When we compared the results of cuff pressure readings as measured by the residents, the results of our study is in variance with the previous studies in that the number of cuff pressure readings in the correct range $(70 \%)$ was more than what is quoted in literature. $(6,7,8,15)$ This could be because of the fact that in our study we have considered resident doctors as a separate subgroup and measured the cuff pressures when inflation of the cuff was done by the resident doctors. We have not found such a study in our literature search.

Vivek Parwani et al in their study in which 53 paramedical personnel were sampled showed that the average pressure generated by inflating the endotracheal tube cuff was $>108 \mathrm{~cm}$ $\mathrm{H}_{2} \mathrm{O}$. Participants were only $13 \%$ sensitive detecting overinflated endotracheal tube cuffs. They concluded that the participants of the study namely the paramedics were unable to inflate endotracheal tube cuff to safe pressures and also were unable to identify endotracheal tube cuffs with excessive intracuff pressure by palpation.(16)

The results of our study with regards to the measurement of the cuff pressure when inflated by paramedical personnel were again in variance with the above study in that out of the 60 readings by paramedical personnel, 16 were $<20 \mathrm{~cm}$ of $\mathrm{H}_{2} \mathrm{O}$ (26.66 \%), 18 were between 20 and $30 \mathrm{~cm}$ of $\mathrm{H}_{2} \mathrm{O}(30 \%)$ and 26 readings were $>30 \mathrm{~cm}$ of $\mathrm{H}_{2} \mathrm{O}(43.33 \%)$. This $30 \%$ correct reading is poorer that the $50 \%$ correct readings reported by Papiya Sengupta et al.(12) However, we did not measure the sensitiveness in detecting overinflated endotracheal tube cuffs as done by Parwani et al.(16)

This study is unique in the fact that we have tried to determine the correctness of endotracheal and tracheostomy cuff inflation by palpation method when done by both the residents and paramedical personnel, and comparing the correctness of each subgroup. The results of this study are comparable to the previous studies when considered in toto but is in variance when we considered the individual subgroups. We observed that the residents were more reliable when compared to the paramedical personnel for the inflation of cuffs by palpatory method. However, even the residents correct pressures achieved only $70 \%$ of the cases.

Therefore, we recommend that monitoring of the cuff pressure by monitor should be routinely done in all patients with endotracheal and tracheostomy tubes in Intensive Care Units and Operation Theatres.

\section{CONCLUSIONS}

From the results of our study, we conclude that inflation of cuff of endotracheal and tracheostomy tubes by palpatory method are not accurate and cannot be relied upon to achieve optimal cuff pressure. We have seen that paramedical personnel tend to be more inaccurate compared to residents.

Based on these results we recommend that monitoring of the cuff pressure by monitor should be routinely done in all patients with endotracheal and tracheostomy tubes in Intensive Care Units and Operation Theatres. This will lead to avoidance of the consequences of overinflation and underinflation. However, this is a small study with limited data and larger similar studies would be necessary to throw more light on this critical issue.

\section{REFERENCES}

1. Myentis S, Hirsh NP, Smith GB. Anesthesia and intensive care A-Z, An encyclopedia of principles and practices. 2nd edn, London: Butterworth Heinemann 2000:p. 150.

2. Haspel KL, Hellmann J, Hess D. Critical care handbook of the Massachusetts General Hospital. $4^{\text {th }}$ edn. New York: Lippincott William and Wilkin 2006:p. 63.

3. Tobin MJ, Grenvik A. Nosocomial lung infection and its diagnosis. Crit Care Med 1984;12(3):191-9.

4. Lien TC, Wang JH. Incidence of pulmonary aspiration with different kinds of artificial airways. Zhonghua Yi Xue Za Zhi (Taipei) 1992;49(5):348-53.

5. Nordin U. The trachea and cuff-induced tracheal injury. An experimental study on causative factors and prevention. Acta Otolaryngol 1977;345:1-71.

6. Healthcare Infection Control Practices Advisory Committee; Centers for Disease Control and Prevention (US). Guidelines for preventing health-care-associated pneumonia, 2003 recommendations of the CDC and the Healthcare Infection Control Practices Advisory Committee. Respir Care 2004;49(8):926-39.

7. Rello J, Soñora R, Jubert $\mathrm{P}$, et al. Pneumonia in intubated patients: role of respiratory airway care. Am J Respir Crit Care Med 1996;154(1):111-5.

8. Safdar N, Dezfulian C, Collard HR, et al. Clinical and economic consequences of ventilator-associated pneumonia: a systematic review. Crit Care Med 2005;33(10):2184-93.

9. Simmons KF, Scanlan CL. Airway management. In: Wilkins RL, Stoller JK, Scanlan CL, eds. Egan's fundamentals of respiratory care. $8^{\text {th }}$ edn. St Louis, MO: Mosby 2003:653704.

10. Diaz E, Rodriguez AH, Rello J. Ventilator-associated pneumonia: issues related to the artificial airway. Respir Care 2005;50(7):900-6.

11. Hamilton VA, Grap MJ. The role of the endotracheal tube cuff in microaspiration. Heart Lung. 2012;41(2):167-72.

12. Sengupta $P$, Sessler DI, Maglinger $P$, et al. Endotracheal tube cuff pressure in three hospitals and the volume required to produce an appropriate cuff pressure. BMC Anesthesiol 2004;29(4):8. 
13. Braz JR, Navarro LH, Takata IH, et al. Endotracheal tube cuff pressure: need for precise measurement. Sao Paulo Med J 1999;117(6):243-7.

14. Fernandez R, Blanch L, Mancebo J, et al. Endotracheal tube cuff pressure assessment: pitfalls of finger estimation and need for objective measurement. Crit Care Med 1990;18(12):1423-6.
15. Morris LG, Zoumalan RA, Roccaforte JD, et al. Monitoring tracheal tube cuff pressures in the intensive care unit: a comparison of digital palpation and manometry. Ann Otol Rhinol Laryngol 2007;116(9):639-42.

16. Parwani V, Hoffman RJ, Russell A, et al. Practicing paramedics cannot generate or estimate safe endotracheal tube cuff pressure using standard techniques. Prehosp Emerg Care 2007;11(3):307-11. 